\title{
Common Fixed Point Iterations of Generalized Asymptotically Quasi-Nonexpansive Mappings in Hyperbolic Spaces
}

\author{
A. R. Khan, H. Fukhar-ud-din \\ Department of Mathematics and Statistics, King Fahd University of Petroleum and Minerals, Dhahran, \\ Saudi Arabia \\ Email: arahim@kfupm.edu.sa, hfdin@kfupm.edu.sa
}

Received December 2013

\section{Abstract}

We introduce a general iterative method for a finite family of generalized asymptotically quasinonexpansive mappings in a hyperbolic space and study its strong convergence. The new iterative method includes multi-step iterative method of Khan et al. [1] as a special case. Our results are new in hyperbolic spaces and generalize many known results in Banach spaces and $C A T(0)$ spaces, simultaneously.

\section{Keywords}

Hyperbolic Space, General Iterative Method, Generalized Asymptotically Quasi-Nonexpansive Mapping, Common Fixed Point, Strong Convergence

\section{Introduction}

Let $C$ be a nonempty subset of a metric space $X$ and $T: C \rightarrow C$ be a mapping. Throughout this paper, we assume that $F(T)$, the set of fixed points of $T$ is nonempty and $I=\{1,2,3, \ldots, r\}$. The mapping $T$ is: 1 ) asymptotically nonexpansive if there exists a sequence of real numbers $\left\{u_{n}\right\}$ in $[0, \infty)$ with $\lim _{n \rightarrow \infty} u_{n}=0$ such that $d\left(T^{n} x, T^{n} y\right) \leq\left(1+u_{n}\right) d(x, y)$ for all $x, y \in C$ and $\left.n \geq 12\right)$ asymptotically quasi-nonexpansive if there exists a sequence of real numbers $\left\{u_{n}\right\}$ in $[0, \infty)$ with $\lim _{n \rightarrow \infty} u_{n}=0$ such that $d\left(T^{n} x, p\right) \leq\left(1+u_{n}\right) d(x, p)$ for all $x \in C, p \in F(T)$ and $n \geq 1$ 3) generalized asymptotically quasi-nonexpansive if there exist two sequences of real numbers $\left\{u_{n}\right\}$ and $\left\{c_{n}\right\}$ in $[0, \infty)$ with $\lim _{n \rightarrow \infty} u_{n}=0=\lim _{n \rightarrow \infty} c_{n}$ such that $d\left(T^{n} x, p\right) \leq d(x, p)+u_{n} d(x, p)+c_{n}$ for all $x \in C, p \in F(T)$ and $n \geq 1$ (iv) uniformly $L$-Lipschitzian if there exists a constant $L>0$ such that $d\left(T^{n} x, T^{n} x\right) \leq L d(x, y)$ for all $x, y \in C$ and $n \geq 1(\mathrm{v})(L-\gamma)-$ 
uniformly Lipschitzian if there are constants $L>0, \gamma>0$ such that $d\left(T^{n} x, T^{n} x\right) \leq L d(x, y)^{\gamma}$ for all $x, y \in C$ and $n \geq 1$ and (vi) semi-compact if for any sequence $\left\{x_{n}\right\}$ in $C$ with $\lim _{n \rightarrow \infty} d\left(x_{n}, T x_{n}\right)=0$, there exists a subsequence $\left\{x_{n_{i}}\right\}$ of $\left\{x_{n}\right\}$ such that $x_{n_{i}} \rightarrow c \in C$.

Let $(X, d)$ be a metric space. Suppose that there exists a family $F$ of metric segments such that any two points $x, y$ in $X$ are endpoints of a unique metric segment $[x, y] \in F[x, y]$ is an isometric image of the real line interval $[0, d(x, y)])$. We shall denote by $\alpha x \oplus(1-\alpha) y$ the unique point $z$ of $[x, y]$ which satisfies

$$
d(x, z)=(1-\alpha) d(x, y) \text { and } d(z, y)=\alpha d(x, y) \text { for } \alpha \in J=[0,1] .
$$

Such metric spaces are usually called convex metric spaces [2] [3]. One can easily deduce that $0 x \oplus 1 y=y$, $1 x \oplus 0 y=x$ and $\alpha x \oplus(1-\alpha) x=x$ from the definition of a convex metric space [2].

A convex metric space $X$ is hyperbolic if

$$
d(\alpha x \oplus(1-\alpha) y, \alpha z \oplus(1-\alpha) w) \leq \alpha d(x, z)+(1-\alpha) d(y, w)
$$

for all $x, y, z, w \in X$ and $\alpha \in J$. For $z=w$, the hyperbolic inequality reduces to convex structure [3].

$$
d(\alpha x \oplus(1-\alpha) y, z) \leq \alpha d(x, z)+(1-\alpha) d(y, z) .
$$

A nonempty subset $C$ of a convex metric space $X$ is convex if $\alpha x \oplus(1-\alpha) y \in C$ for all $x, y \in C$ and $\alpha \in J$.

Normed spaces and their subsets are linear hyperbolic spaces while CAT(0) spaces [4]-[6] qualify for the criteria of nonlinear hyperbolic spaces [2] [7].

A convex metric space $X$ is uniformly convex [7] if

$$
\delta(r, \varepsilon)=\inf \left\{1-\frac{1}{r} d\left(a, \frac{1}{2} x \oplus \frac{1}{2} y\right): d(a, x) \leq r, d(a, y) \leq r, d(x, y) \geq r \varepsilon\right\}>0,
$$

for any $a \in X, r>0$ and $\varepsilon>0$.

From now onwards we assume that $X$ is a uniformly convex hyperbolic space with the property that for every $s \geq 0, \varepsilon>0$, there exists $\eta(s, \varepsilon)>0$ depending on $s$ and $\varepsilon$ such that $\delta(r, \varepsilon)>\eta(s, \varepsilon)>0$ for any $r>s$.

We now translate the iterative method (1.3) [1] from normed space setting to the more general setup of hyperbolic space as follows:

$$
x_{1} \in C, x_{n+1}=U_{r n} x_{n}, n \geq 1
$$

where

$$
\begin{aligned}
& U_{0 n}=I \text { (the identity mapping) } \\
& U_{1 n} x=a_{1 n} T_{1}^{n} U_{0 n} x \oplus\left(1-a_{1 n}\right) x \\
& U_{2 n} x=a_{2 n} T_{2}^{n} U_{1 n} x \oplus\left(1-a_{2 n}\right) x \\
& \vdots \\
& U_{r n} x=a_{r n} T_{r}^{n} U_{(r-1) n} x \oplus\left(1-a_{r n}\right) x
\end{aligned}
$$

and $\left\{T_{i}: i \in I\right\}$ is a family of generalized asymptotically quasi-nonexpansive self-mappings of $C$, i.e., $d\left(T_{i}^{n} x, p_{i}\right) \leq\left(1+u_{i n}\right) d\left(x, p_{i}\right)+c_{i n}$ for all $x \in C$ and $p_{i} \in F\left(T_{i}\right), i \in I,\left\{u_{i n}\right\}$ and $\left\{c_{i n}\right\}$ are sequences in $[0, \infty)$ with $\sum_{n=1}^{\infty} u_{i n}<\infty$ and $\sum_{n=1}^{\infty} c_{i n}<\infty$ for each $i$.

The purpose of this paper is to:

1) establish convergence of iterative method (1.2) to a common fixed point of a finite family of generalized asymptotically quasi-nonexpansive mappings on a hyperbolic space(uniformly convex hyperbolic space).

Our work is a significant generalization of the corresponding results in Banach spaces and $C A T(0)$ spaces.

In the sequel, we assume that $F=\bigcap_{i \in I} F\left(T_{i}\right) \neq \varnothing$.

\section{Convergence Theorems in Hyperbolic Space}

Lemma 2.1. Let $C$ be a nonempty, closed and convex subset of a hyperbolic space $X$. Then, for the sequence 
$\left\{x_{n}\right\}$ in (1.2), there are sequences $\left\{v_{n}\right\}$ and $\left\{\xi_{n}\right\}$ in $[0, \infty)$ satisfying $\sum_{n=1}^{\infty} v_{n}<\infty, \sum_{n=1}^{\infty} \xi_{n}<\infty$ such that

1) $d\left(x_{n+1}, p\right) \leq\left(1+v_{n}\right) d\left(x_{n}, p\right)+\xi_{n}$, for all $p \in F$ and all $n \geq 1$

2) $d\left(x_{n+m}, p\right) \leq M_{1}\left(d\left(x_{n}, p\right)+\sum_{n=1}^{\infty} \xi_{n}\right)$, for all $p \in F$ and $n \geq 1, m \geq 1, M_{1}>0$.

Proof. (a) Let $p \in F$ and $v_{n}=\max _{i \in I} u_{i n}$ for all $n \geq 1$. Since $\sum_{n=1}^{\infty} u_{i n}<\infty$ for each $i$, therefore $\sum_{n=1}^{\infty} v_{n}<\infty$.

Now we have

$$
\begin{aligned}
& d\left(U_{1 n} x_{n}, p\right)=d\left(a_{1 n} T_{1}^{n} U_{0 n} x_{n} \oplus\left(1-a_{1 n}\right) x_{n}, p\right) \leq\left(1-a_{1 n}\right) d\left(x_{n}, p\right)+a_{1 n} d\left(T_{1}^{n} x_{n}, p\right) \\
& \leq\left(1-a_{1 n}\right) d\left(x_{n}, p\right)+a_{1 n}\left[\left(1+u_{1 n}\right) d\left(x_{n}, p\right)+c_{1 n}\right] \leq\left(1+u_{1 n}\right) d\left(x_{n}, p\right)+c_{1 n} \leq\left(1+v_{n}\right)^{1} d\left(x_{n}, p\right)+c_{1 n} .
\end{aligned}
$$

Assume that $d\left(U_{k n} x_{n}, p\right) \leq\left(1+v_{n}\right)^{k} d\left(x_{n}, p\right)+\left(1+v_{n}\right)^{k-1} \sum_{i=1}^{k} c_{i n}$ holds for some $k>1$.

Consider

$$
\begin{aligned}
& d\left(U_{(k+1) n} x_{n}, p\right)=d\left(a_{(k+1) n} T_{k+1}^{n} U_{k n} x_{n} \oplus\left(1-a_{(k+1) n}\right) x_{n}, p\right) \leq\left(1-a_{(k+1) n}\right) d\left(x_{n}, p\right)+a_{(k+1) n} d\left(T_{k+1}^{n} U_{k n} x_{n}, p\right) \\
& \leq\left(1-a_{(k+1) n}\right) d\left(x_{n}, p\right)+a_{(k+1) n}\left(1+u_{(k+1) n}\right) d\left(U_{k n} x_{n}, p\right)+a_{(k+1) n} c_{(k+1) n} \\
& \leq\left(1-a_{(k+1) n}\right) d\left(x_{n}, p\right)+a_{(k+1) n} c_{(k+1) n}+a_{(k+1) n}\left(1+u_{(k+1) n}\right) d\left(U_{k n} x_{n}, p\right) \\
& \leq\left(1-a_{(k+1) n}\right) d\left(x_{n}, p\right)+a_{(k+1) n} c_{(k+1) n}+a_{(k+1) n}\left(1+v_{n}\right)\left[\left(1+v_{n}\right)^{k} d\left(x_{n}, p\right)+\left(1+v_{n}\right)^{k-1} \sum_{i=1}^{k} c_{i n}\right] \\
& \leq\left(1-a_{(k+1) n}\right)\left(1+v_{n}\right)^{k+1} d\left(x_{n}, p\right)+a_{(k+1) n}\left(1+v_{n}\right) c_{(k+1) n}+a_{(k+1) n}\left(1+v_{n}\right)^{k+1} d\left(x_{n}, p\right)+a_{(k+1) n}\left(1+v_{n}\right)^{k-1} \sum_{i=1}^{k+1} c_{i n} \\
& \leq\left(1+v_{n}\right)^{k+1} d\left(x_{n}, p\right)+\left(1+v_{n}\right)^{k} \sum_{i=1}^{k+1} c_{i n}
\end{aligned}
$$

By mathematical induction, we have

$$
d\left(U_{j n} x_{n}, p\right) \leq\left(1+v_{n}\right)^{j} d\left(x_{n}, p\right)+\left(1+v_{n}\right)^{j-1} \sum_{i=1}^{j} c_{i n}, 1 \leq j \leq r .
$$

Now, by (1.2) and (2.1), we obtain

$$
\begin{aligned}
& d\left(x_{n+1}, p\right)=d\left(a_{r n} T_{r}^{n} U_{(r-1) n} x \oplus\left(1-a_{r n}\right) x, p\right) \\
& \leq a_{r n} d\left(T_{r}^{n} U_{(r-1) n} x_{n}, p\right)+\left(1-a_{r n}\right) d\left(x_{n}, p\right) \\
& \leq a_{r n}\left[\left(1+u_{r n}\right) d\left(U_{(r-1) n} x_{n}, p\right)+c_{r n}\right]+\left(1-a_{r n}\right) d\left(x_{n}, p\right) \\
& \leq a_{r n}\left(1+u_{r n}\right)\left[\left(1+v_{n}\right)^{r-1} d\left(x_{n}, p\right)+\left(1+v_{n}\right)^{r-2} \sum_{i=1}^{r-1} c_{i n}\right]+a_{r n} c_{r n}+\left(1-a_{r n}\right) d\left(x_{n}, p\right) \\
& \leq a_{r n}\left(1+v_{n}\right)^{r} d\left(x_{n}, p\right)+a_{r n}\left(1+v_{n}\right)^{r-1} \sum_{i=1}^{r} c_{i n} c_{i n}+\left(1-a_{r n}\right) d\left(x_{n}, p\right) \\
& \leq\left[1-a_{r n}+a_{r n}\left(1+v_{n}\right)^{r}\right] d\left(x_{n}, p\right)+a_{r n}\left(1+v_{n}\right)^{r-1} \sum_{i=1}^{r} c_{i n} \\
& =\left[1-a_{r n}+a_{r n} \sum_{k=1}^{r}\left(1+\frac{(r(r-1) \ldots(r-k+1))}{k !} v_{n}^{k}\right)\right] d\left(x_{n}, p\right)+a_{r n}\left(1+v_{n}\right)^{r-1} \sum_{i=1}^{r-1} c_{i n} \\
& \leq\left(1+v_{n}\right)^{r} d\left(x_{n}, p\right)+\left(1+v_{n}\right)^{r-1} \sum_{i=1}^{r} c_{i n} \leq\left(1+v_{n}\right)^{r} d\left(x_{n}, p\right)+\xi_{n},
\end{aligned}
$$

Where $M=\sup M=\sup \left(1+v_{n}\right)^{r-1}, \xi_{n}=M \sum_{i=1}^{r} c_{i n}$ and $\sum_{n=1}^{\infty} \xi_{n}<\infty$.

(b) We know that $1+t \leq \exp t$ for $t \geq 0$. Thus, by part (a), we have 


$$
\begin{aligned}
& d\left(x_{n+m}, p\right) \leq\left(1+v_{n+m-1}\right)^{r} d\left(x_{n+m-1}, p\right)+\xi_{n+m-1} \\
& \leq \exp \left(r v_{n+m-1}\right) d\left(x_{n+m-1}, p\right)+\xi_{n+m-1} \\
& \leq \exp \left(r v_{n+m-1}+r v_{n+m-2}\right) d\left(x_{n+m-2}, p\right)+\xi_{n+m-1}+\xi_{n+m-2} \\
& \vdots \\
& \leq \exp \left(r \sum_{i=n}^{n+m-1} v_{i}\right) d\left(x_{n}, p\right)+\sum_{i=n+1}^{n+m-1} v_{i} \sum_{i=n}^{n+m-1} \xi_{i} \\
& \leq \exp \left(r \sum_{i=1}^{\infty} v_{i}\right)\left(d\left(x_{n}, p\right)+\sum_{i=1}^{\infty} \xi_{i}\right)=M_{1}\left(d\left(x_{n}, p\right)+\sum_{i=1}^{\infty} \xi_{i}\right), \\
& \text { where } M_{1}=\exp \left(r \sum_{i=1}^{\infty} v_{i}\right) .
\end{aligned}
$$

Theorem 2.2. Let $C$ be a nonempty, closed and convex subset of a complete hyperbolic space $X$. Then the sequence $\left\{x_{n}\right\}$ in (1.2) converges strongly to a point in $F$ if and only if $\liminf _{n \rightarrow \infty} d\left(x_{n}, F\right)=0$, where $d(x, F)=\inf _{p \in F} d(x, p)$.

Proof. We only prove the sufficiency. By Lemma 2.1 (a), we have

$d\left(x_{n+1}, p\right) \leq\left(1+v_{n}\right)^{r} d\left(x_{n}, p\right)+\xi_{n}$ for all $p \in F$ and $n \geq 1$. Therefore,

$$
d\left(x_{n+1}, F\right) \leq\left(1+\sum_{k=1}^{r}((r(r-1) \ldots(r-k+1)) / k !) v_{n}^{k}\right) d\left(x_{n}, F\right)+\xi_{n}
$$

As $\sum_{n=1}^{\infty} v_{n}<\infty$, so $\sum_{n=1}^{\infty} \sum_{k=1}^{r}((r(r-1) \ldots(r-k+1)) / k !) v_{n}^{k}<\infty$. Now $\sum_{n=1}^{\infty} \xi_{n}<\infty$ in Lemma 2.1 (a), so by Lemma 1.1 [1] and $\liminf _{n \rightarrow \infty} d\left(x_{n}, F\right)=0$, we get that $\lim _{n \rightarrow \infty} d\left(x_{n}, F\right)=0$. Let $\varepsilon>0$. From the proof of Lemma 2.1 (b), we have

$$
d\left(x_{n+m}, x_{n}\right) \leq d\left(x_{n+m}, F\right)+d\left(x_{n}, F\right) \leq\left(1+M_{1}\right) d\left(x_{n}, F\right)+M_{1} \sum_{i=n}^{\infty} \xi_{i}
$$

Since $\lim _{n \rightarrow \infty} d\left(x_{n}, F\right)=0$ and $\sum_{i=n}^{\infty} \xi_{i}<\infty$, therefore there exists a natural number $n_{0}$ such that $d\left(x_{n}, F\right) \leq \varepsilon / 2\left(1+M_{1}\right)$ and $\sum_{i=n}^{\infty} \xi_{i}<\varepsilon / 2 M_{1}$ for all $n \geq n_{0}$.

So for all integers $n \geq n_{0}, m \geq 1$, we obtain from (2.2) that

$$
d\left(x_{n+m}, x_{n}\right) \leq\left(1+M_{1}\right)\left(\varepsilon / 2\left(1+M_{1}\right)\right)+M_{1}\left(\varepsilon / 2 M_{1}\right)=\varepsilon .
$$

Thus, $\left\{x_{n}\right\}$ is a Cauchy sequence in $X$ and so converges to $q \in X$. Finally, we show that $q \in F$. For any $\bar{\varepsilon}>0$, there exists natural number $n_{1}$ such that $d\left(x_{n}, F\right)=\inf _{p \in F} d\left(x_{n}, p\right)<\bar{\varepsilon} / 3$ and $d\left(x_{n}, q\right)<\bar{\varepsilon} / 2$ for all $n \geq n_{1}$.

There must exist $p^{*} \in F$ such that $d\left(x_{n}, p^{*}\right)<\bar{\varepsilon} / 2$ for all $n \geq n_{1}$, in particular, $d\left(x_{n 1}, p^{*}\right)<\bar{\varepsilon} / 2$ and $d\left(x_{n 1}, q\right)<\bar{\varepsilon} / 2$.

Hence $d\left(p^{*}, q\right) \leq d\left(x_{n 1}, p^{*}\right)+d\left(x_{n 1}, q\right)<\bar{\varepsilon}$. Since $\bar{\varepsilon}$ is arbitrary, therefore $d\left(p^{*}, q\right)=0$. That is, $q=p^{*} \in F$.

Theorem 2.3. Let $C$ be a nonempty, closed and convex subset of a complete convex metric space $X$, If $\lim _{n \rightarrow \infty} d\left(x_{n}, T_{i} x_{n}\right)=0$ for the sequence $\left\{x_{n}\right\}$ in (1.2), $i \in I$ and one of the mappings is semi-compact, then $\left\{x_{n}\right\}$ converges strongly to $p \in F$.

Proof. Let $T_{l}$ be semi-compact for some $1 \leq l \leq r$. Then there exists a subsequence $\left\{x_{i}\right\}$ of $\left\{x_{n}\right\}$ such that $x_{i} \rightarrow p \in C$. Hence

$$
d\left(p, T_{l} p\right)=\lim _{n_{j \rightarrow \infty}} d\left(x_{i}, T_{l} x_{i}\right)=0 .
$$

Thus $p \in F$ and so by Theorem 2.2, $\left\{x_{n}\right\}$ converges strongly to a common fixed point of the family of mappings. 


\section{Results in a Uniformly Convex Hyperbolic Space}

Lemma 3.1.Let $C$ be a nonempty, closed and convex subset of a uniformly convex hyperbolic space $X$. Then, for the sequence $\left\{x_{n}\right\}$ in (1.2) with $a_{i n} \in[\delta, 1-\delta]$ for some $\delta \in\left(0, \frac{1}{2}\right)$, we have

(a) $\lim _{n \rightarrow \infty} d\left(x_{n}, p\right)$ exists for all $p \in F$

(b) $\lim _{n \rightarrow \infty} d\left(x_{n}, T_{j} x_{n}\right)=0$, for each $j \in I$.

Proof. (a) Let $p \in F$ and $v_{n}=\max _{i \in I} u_{i n}$, for all $n \geq 1$.By Lemma 1.1 [1] and Lemma 2.1 (a), it follows that $\lim _{n \rightarrow \infty} d\left(x_{n}, p\right)$ exists. Assume that

$$
\lim _{n \rightarrow \infty} d\left(x_{n}, p\right)=c .
$$

(b) The inequality (2.1) together with (3.1) gives that

$$
\limsup _{n \rightarrow \infty} d\left(U_{j n} x_{n}, p\right) \leq c, 1 \leq j \leq r .
$$

Note that

$$
\begin{aligned}
& d\left(x_{n+1}, p\right)=d\left(U_{r n} x_{n}, p\right)=d\left(a_{r n} T_{r}^{n} U_{(r-1) n} x_{n} \oplus\left(1-a_{r n}\right) x_{n}, p\right) \\
& \leq a_{r n}\left[\left(1+v_{n}\right) d\left(U_{(r-1) n} x_{n}, p\right)+c_{r n}\right]+\left(1-a_{r n}\right) d\left(x_{n}, p\right) \\
& =a_{r n}\left(1+v_{n}\right) d\left(a_{(r-1) n} T_{r-1}^{n} U_{(r-2) n} x_{n} \oplus 1-a_{(r-1) n} x_{n}, p\right)+a_{r n} c_{r n}+\left(1-a_{r n}\right) d\left(x_{n}, p\right) \\
& \leq a_{r n}\left(1+v_{n}\right)\left[a_{(r-1) n} d\left(T_{r-1}^{n} U_{(r-2) n} x_{n}, p\right)+\left(1-a_{(r-1) n}\right) d\left(x_{n}, p\right)\right]+a_{r n} c_{r n}+\left(1-a_{r n}\right) d\left(x_{n}, p\right) \\
& \leq a_{r n} a_{(r-1) n}\left(1+v_{n}\right)^{2} d\left(U_{(r-2) n} x_{n}, p\right)+\left(1-a_{r n} a_{(r-1) n}\right)\left(1+v_{n}\right)^{2} d\left(x_{n}, p\right) \\
& +a_{r n} a_{(r-1) n}\left(1+v_{n}\right)^{2} c_{(r-1) n}+a_{r n}\left(1+v_{n}\right)^{2} c_{r n} \\
& \leq \prod_{i=j+1}^{r} a_{i n}\left(1+v_{n}\right)^{r-j} d\left(U_{j n} x_{n}, p\right)+\left(1-\prod_{i=j+1}^{r} a_{i n}\right)\left(1+v_{n}\right)^{r-j} d\left(x_{n}, p\right) \\
& +\prod_{i=j+1}^{r} a_{i n}\left(1+v_{n}\right)^{r-j} c_{(j+1) n}+\prod_{i=j+2}^{r} a_{i n}\left(1+v_{n}\right)^{r-j} c_{j n}+\ldots+a_{r n}\left(1+v_{n}\right)^{r-j} c_{r n} .
\end{aligned}
$$

and therefore, we have

$$
d\left(x_{n}, p\right) \leq\left(d\left(x_{n}, p\right) / \delta^{r-j}\right)-\left(d\left(x_{n+1}, p\right) / \delta^{r-j}\left(1+v_{n}\right)^{r-j}\right)+d\left(U_{j n} x_{n}, p\right)+c_{(j+1) n}+\left(c_{j n} / \delta\right)+\cdots+c_{r n} / \delta^{r-j+1}
$$

Hence

$$
c \leq \liminf _{n \rightarrow \infty} d\left(U_{j n} x_{n}, p\right), 1 \leq j \leq r .
$$

Using (3.2) and (3.3), we have $\lim _{n \rightarrow \infty} d\left(U_{j n} x_{n}, p\right)=c$.

That is, $\lim _{n \rightarrow \infty} d\left(a_{j n} T_{j}^{n} U_{(j-1) n} x_{n} \oplus\left(1-a_{j n}\right) x_{n}, p\right)=c$ for $1 \leq j \leq r$.

This together with (3.1), (3.2) and Lemma 2.5 [8] gives that

$$
\lim _{n \rightarrow \infty} d\left(T_{j}^{n} U_{(j-1) n} x_{n}, x_{n}\right)=0 \text { for } 1 \leq j \leq r .
$$

If $j=1$, we have by (3.4), $\lim _{n \rightarrow \infty} d\left(T_{1}^{n} x_{n}, x_{n}\right)=0$.

In case $j \in\{2,3,4, \cdots, r\}$, we observe that

$$
d\left(x_{n}, U_{(j-1) n} x_{n},\right)=d\left(x_{n}, a_{(j-1) n} T_{j-1}^{n} U_{(j-2) n} x_{n} \oplus\left(1-a_{(j-1) n}\right) x_{n}\right) \leq a_{(j-1) n} d\left(T_{j-1}^{n} U_{(j-2) n} x_{n}, x_{n}\right) \rightarrow 0
$$


Since $T_{j}$ is $(L-\gamma)-$ uniformly Lipschitzian, therefore the inequality

$$
d\left(T_{j}^{n} x_{n}, x_{n}\right) \leq d\left(T_{j}^{n} x_{n}, T_{j}^{n} U_{(j-1) n} x_{n}\right)+d\left(T_{j}^{n} U_{(j-1) n} x_{n}, x_{n}\right) \leq L d\left(x_{n} U_{(j-1) n} x_{n}\right)^{\gamma}+d\left(T_{j}^{n} U_{(j-1) n} x_{n}, x_{n}\right),
$$

together with (3.4) and (3.5) gives that $\lim _{n \rightarrow \infty} d\left(T_{j}^{n} x_{n}, x_{n}\right)=0$.

Hence,

$$
d\left(T_{j}^{n} x_{n}, x_{n}\right) \rightarrow 0 \text { asn } \rightarrow \infty \text { for } 1 \leq j \leq r .
$$

Note that $d\left(x_{n}, x_{n+1}\right)=d\left(x_{n}, a_{r n} T_{r}^{n} U_{(r-1) n} x_{n n} \oplus\left(1-a_{r n}\right) x_{n}\right) \leq a_{r n} d\left(x_{n}, T_{r}^{n} U_{(r-1) n} x_{n}\right) \rightarrow 0$.

Let us observe that:

$$
\begin{aligned}
& d\left(x_{n}, T_{j} x_{n}\right) \leq d\left(x_{n}, x_{n+1}\right)+d\left(x_{n+1}, T_{j}^{n+1} x_{n+1}\right)+d\left(T_{j}^{n+1} x_{n+1}, T_{j}^{n+1} x_{n}\right)+d\left(T_{j}^{n+1} x_{n}, T_{j} x_{n}\right) \\
& \leq d\left(x_{n}, x_{n+1}\right)+d\left(x_{n+1}, T_{j}^{n+1} x_{n+1}\right)+L d\left(x_{n+1}, x_{n}\right)^{\gamma}+L d\left(T_{j}^{n} x_{n}, x_{n}\right)^{\gamma} .
\end{aligned}
$$

So by $(L-\gamma)$ - uniformly Lipschitzian property of $T_{j}$, (3.5) and (3.6), we get $\lim _{n \rightarrow \infty} d\left(x_{n}, T_{j} x_{n}\right)=0,1 \leq j \leq r$.

Theorem 3.2. Under the hypotheses of Lemma 3.1, assume that, for some $1 \leq j \leq r, T_{j}^{m}$ is semi-compact for some positive integer $m$. Then $\left\{x_{n}\right\}$ in (1.2), converges strongly to a point in $F$.

Proof. Fix $j \in I$ and suppose $T_{j}^{m}$ is semi-compact for some $m \geq 1$. By Lemma 3.1 (b), we obtain

$$
\begin{aligned}
& d\left(T_{j}^{m} x_{n}, x_{n}\right) \leq d\left(T_{j}^{m} x_{n}, T_{j}^{m-1} x_{n}\right)+d\left(T_{j}^{m-1} x_{n}, T_{j}^{m-2} x_{n}\right)+\cdots+d\left(T_{j}^{2} x_{n}, T_{j} x_{n}\right)+d\left(T_{j} x_{n}, x_{n}\right) \\
& \leq d\left(T_{j} x_{n}, x_{n}\right)+(m-1) L d\left(T_{j} x_{n}, x_{n}\right)^{\gamma} \rightarrow 0 .
\end{aligned}
$$

Since $\left\{x_{n}\right\}$ is bounded and $T_{j}^{m}$ is semi-compact, $\left\{x_{n}\right\}$ has a convergent subsequence $\left\{x_{n_{i}}\right\}$ such that $x_{n_{i}} \rightarrow q \in C$. Hence, by Lemma 3.1 (b), we have $d\left(q, T_{i} q\right)=\lim _{n \rightarrow \infty} d\left(x_{n_{j}}, T_{i} x_{n_{j}}\right)=0, i \in I$.

Thus $q \in F$ and so by Theorem 2.2, $\left\{x_{n}\right\}$ converges strongly to a common fixed point $q$ of the family $\left\{T_{i}: i \in I\right\}$.

\section{Acknowledgements}

The author A. R. Khan is grateful to KACST for supporting the research project ARP-32-34. The author H. Fukhar-ud-din acknowledges King Fahd University of Petroleum \& Minerals for supporting research project IN121037.

\section{References}

[1] Khan, A.R., Domlo, A.A. and Fukhar-ud-din, H. (2008) Common Fixed Points Noor Iteration for a Finite Family of Asymptotically Quasi-Nonexpansive Mappings in Banach Space. Journal of Mathematical Analysis and Applications. 341, 1-11. http://dx.doi.org/10.1016/j.jmaa.2007.06.051

[2] Menger, K. (1928) Untersuchungenüberallgemeine Metrik. Mathematische Annalen, 100, 75-163. http://dx.doi.org/10.1007/BF01448840

[3] Takahashi, W. (1970) A Convexity in Metric Spaces and Nonexpansive Mappings. Kodai. Math Sem. Rep., 22, 142-149. http://dx.doi.org/10.2996/kmj/1138846111

[4] Bridson, M. and Haefliger, A. (1999) Metric Spaces of Non-Positive Curvature. Springer-Verlag, Berlin, Heidelberg, New York. http://dx.doi.org/10.1007/978-3-662-12494-9

[5] Fukhar-ud-din, H. (2013) Strong Convergence of an Ishikawa-type Algorithm inCAT (0) Spaces. Fixed Point Theory and Applications, 2013, 207.

[6] Khan, A.R., Khamsi, M.A. and Fukhar-ud-din, H. (2011) Strong Convergence of a General Iteration Scheme in CAT(0) Spaces, Nonlinear Anal. 74, 783-791. http://dx.doi.org/10.1016/j.na.2010.09.029

[7] Goebel, K. and Reich, S. (1984) Uniform Convexity, Hyperbolic Geometry, and Nonexpansive Mappings. Series of Monographs and Textbooks in Pure and Applied Mathematics, Dekker, New York.

[8] Khan, A.R., Fukhar-ud-din, H. and Khan, M.A.A. (2012) An Implicit Algorithm for Two Finite Families of Nonexpansive Maps in Hyperbolic Spaces. Fixed Point Theory and Applications, 2012, 54. 